Jurnal Ilmu Komunikasi UHO : Jurnal Penelitian Kajian Ilmu Komunikasi dan Informasi. Volume 6, No. 2, April 2021, hlm 141-155

\title{
ANALISIS ELEMEN BUDAYA KOLEKTIVIS PADA IKLAN COVID-19 KEMENTERIAN KESEHATAN REPUBLIK INDONESIA
}

\author{
David Randy \\ Magister Ilmu Komunikasi, Universitas Budi Luhur \\ Ciledug Raya, Petukangan Utara, Pesanggrahan, Jakarta Selatan, Indonesia 12260
}

\begin{abstract}
ABSTRAK
Tinggat keterinfeksian dan angka kematian akibat Covid-19 yang tinggi di Tiongkok sepanjang Januari hingga Februari 2020 menyebabkan negara-negara di dunia mulai mensosialisasikan pedoman pencegahan penyebaran. Iklan tentang Covid-19 dikemas dengan berbeda di setiap negara, berdasarkan latar belakang budaya tiap-tiap negara. Sebagai negara ketimuran, iklan Covid-19 di Indonesia diduga mengandung unsur-unsur budaya kolektivis. Berdasarkan laporan indeks budaya tahunan Prof. Hofstede, Indonesia dan Pakistan menempati posisi keenam sebagai negara paling kolektif dari 66 negara yang diteliti. Penelitian ini bertujuan untuk mengkaji relevansi dari hasil penilaian tersebut dengan menganalisis unsur-unsur budaya kolektivis pada iklan resmi Covid-19 versi Kementerian Kesehatan (KEMKES) Republik Indonesia. Metode yang digunakan adalah analisis semiotik model Ferdinand De Saussure. Hasil penelitian menunjukkan bahwa iklan KEMKES disusun secara sederhana, menggunakan kalimat langsung, namun sejumlah diksi bermakna luas dan perlu interpretasi lebih lanjut. Pesan pada iklan berorientasi pada kepentingan publik, mengindikasikan unsur-unsur budaya kolektivis yang dominan. Penelitian multidisiplin diperlukan untuk dapat merumuskan model iklan yang lebih universal sehingga dapat menjangkau khalayak yang lebih luas.
\end{abstract}

Kata-kata Kunci: Analisis Semiotika; Covid-19; Iklan; Ferdinand De Saussure; Teori Konteks. 
Jurnal Ilmu Komunikasi UHO : Jurnal Penelitian Kajian Ilmu Komunikasi dan Informasi.

Volume 6, No. 2, April 2021, hlm 141-155

\title{
ANALYSIS OF COLLECTIVE CULTURAL ELEMENTS IN THE INDONESIAN MINISTRY OF HEALTH'S COVID-19 ADVERTISEMENT
}

\begin{abstract}
The high level of infection and mortality rates due to the Covid-19 epidemic in China between January and February 2020 caused countries worldwide to start socializing guidelines to prevent the spreading. Ads about Covid-19 are packaged differently in each country, based on the cultural background of each country. As an eastern country, Covid-19 advertisements in Indonesia are thought to contain collective cultural elements. Based on Prof. Hofstede's annual cultural index report, Indonesia and Pakistan occupy the sixth position as the most collectivist countries of the 66 countries analyzed. This study aims to examine the relevance of the previous survey by analyzing collectivist cultural elements in the Indonesian Ministry of Health's official Covid-19 advertisement. The method used is Ferdinand De Saussure's semiotic analysis model. The results showed that KEMKES' advertisement was arranged in a simple manner, using direct sentences. However, a few diction had broad meanings and needed further interpretation. The message on the ad is publicinterest oriented, indicating the elements of a dominant collectivist culture. Multidisciplinary research is needed to formulate a universal advertising model so that it can reach a wider audience.
\end{abstract}

Keywords: Advertisement; Context Culture Theory; Covid-19; Ferdinand De Saussure; Semiotic Analysis. 
Jurnal Ilmu Komunikasi UHO : Jurnal Penelitian Kajian Ilmu Komunikasi dan Informasi. Volume 6, No. 2, April 2021, hlm 141-155

PENDAHULUAN

Coronavirus 2 atau SARS-CoV-2 yang juga dikenal sebagai Coronavirus 2019 (Covid19) mulai menjadi perhatian dunia pada pertengahan Februari 2020 karena persebaran yang cepat dan tingkat keterinfeksian yang tinggi. Sejak itu, Covid-19 tidak hanya menginfeksi lebih dari 118 juta orang di 200 negara dan teritori, tetapi juga telah menewaskan lebih dari 2,62 juta jiwa. Hingga pekan pertama Maret 2021, terdapat lebih dari 1,3 juta kasus positif di Indonesia, di mana lebih dari 37 ribu orang telah meninggal dunia (Google News, 7/3/2021).

Pasca diumumkannya kasus positif pertama di Indonesia pada 1 Maret 2020, pemerintah dan media massa mulai mensosialisasikan perkembangan kasus serta ajakan kepada masyarakat untuk menghentikan penyebaran virus. Adapun iklan layanan masyarakat resmi pertama yang dipublikasikan oleh Kementerian Kesehatan (KEMENKES) Republik Indonesia berjudul Iklan Layanan Masyarakat Terkait Pencegahan Covid-19. Iklan tersebut berupa poster ajakan sederhana yang dipublikasikan pertama kali pada 7 Maret 2020 di situs KEMENKES, yang kemudian disusul dengan video ilustrasi rincian langkah-langkah pencegahan pada 15 Maret 2020, empat hari pasca KEMENKES mempublikasikan poster panduan dari Badan Kesehatan Dunia (WHO).

Sejumlah penelitian terdahulu menunjukkan bahwa pesan pada iklan yang ditargetkan pada orang-orang di belahan dunia tertentu umumnya tidak dapat menjangkau orang di wilayah lain, karenanya diperlukan standarisasi pesan yang dapat menjangkau khalayak yang lebih luas (Hornikx dan Le Pair, 2017: 228). Chomsky berpendapat bahwa bahasa merupakan penemuan budaya (Stewart dan Strathern, 2017: 69). Hasil penelitian Novikova dkk. menyimpulkan bahwa konsep linguistik dan budaya menyampaikan norma-norma perilaku dan nilai-nilai dalam masyarakat pada tahap perkembangannya (Novikova, dkk., 2018: 241).

Atas dasar tersebut, penulis berusaha untuk menguji agumentasi bahwa bahasa mewakili budaya penggunanya. Berdasarkan asumsi tersebut, pesan pada iklan dipengaruhi oleh latar belakang budaya dan referensi komunikator (pembuat pesan). Artinya unsur-unsur budaya kolektivis yang identik dengan negara-negara Asia, termasuk Indonesia, dapat dilihat atau akan terwakili pada iklan layanan masyarakat yang dipublikasikan KEMENKES. Oleh karena itu, penelitian ini bertujuan untuk mengidentifikasi unsur-unsur budaya kolektivis pada iklan pencegahan Covid-19 versi Kementerian Kesehatan (KEMKES) Republik Indonesia dan mengkaji relevansinya dengan laporan tahunan indeks budaya Prof. Hofstede.

Vera menjelaskan bahwa representasi merupakan gambaran tentang suatu hal yang terdapat dalam kehidupan yang digambarkan melalui suatu media (Vera, 2015: 96). Menurut 
Jurnal Ilmu Komunikasi UHO : Jurnal Penelitian Kajian Ilmu Komunikasi dan Informasi.

Volume 6, No. 2, April 2021, hlm 141-155

Hall, representation is an essential part of how meaning is produced and exchanged between members of a culture (Hall, 2015: 15). Maka, representasi ialah bagian penting dari bagaimana makna diproduksi dan dipertukarkan di antara anggota suatu budaya. Representasi berarti menggunakan bahasa untuk mengatakan sesuatu yang bermakna atau mewakili dunia secara bermakna kepada orang lain (Hall, ibid).

Menurut Barker, representasi merupakan konstruksi sosial yang menuntut masyarakat untuk mengeksplorasi pembentukan makna tekstual dan menyelidiki bagaimana makna dihasilkan dalam berbagai konteks (Vera, 2015: 97). Singkatnya, representasi budaya adalah realitas terkonstruksi dari dunia sosial di mana bahasa digunakan untuk mengatakan sesuatu yang bermakna atau merepresentasikan dunia secara bermakna kepada orang lain. Tradisi Haroa misalnya, berdasarkan penelitian Balsin, Jumaidin dan Masrul (2018), diketahui bahwa tata cara dan tata upacaranya menggunakan simbol-simbol yang representasi dari esensi dan substansi budaya masyarakat suku Buton.

Penelitian Hornikx dan Le Pair yang penulis jadikan rujukan meneliti tentang pengaruh budaya konteks tinggi dan rendah pada iklan pemasaran. Metode yang mereka gunakan ialah survei kuantitatif. Penelitian Novikova et al. meneliti karakteristik leksikon dan semantik dari konsep budaya "rest" pada iklan perjalanan dalam bahasa Inggris, Jerman, dan Rusia. Metode yang digunakan adalah alanisis komperatif linguistik. Sedangkan studi yang dilakukan Balsin, Jumaidin dan Masrul meneliti ritual tradisi Haroa pada masyarakat suku Buton dengan menggunakan metode analisis semiotika Charles Sanders Pierce.

Sementara itu, penelitian yang penulis lakukan meneliti tanda-tanda yang representasikan budaya kolektivis pada iklan layanan masyarakat tentang Covid-19 yang dipublikasi oleh Kementerian Kesehatan (KEMKES) Republik Indonesia mengunakan metode analisis semiotika Ferdinand De Saussure. Dengan demikian, tidak hanya subjek tetapi juga objek penelitian ini berbeda dengan penelitian-penelitian terdahulu. Saat studi ini dilakukan, belum ada kajian lain yang meneliti iklan layanan masyarakat versi KEMKESRI yang dapat dijadikan rujukan.

Menurut Hall, culture is defined as something that embodies the 'best that has been thought and said,' in society (Hall, 2015: 2). Dapat diartikan bahwa budaya merupakan sesuatu yang mengandung 'yang terbaik yang telah dipikirkan dan dikatakan,' dalam masyarakat. Hall berargumentasi bahwa dalam konteks yang lebih modern, budaya mengacu pada bentuk intelektual populer, penerbitan, seni, desain, hiburan, atau waktu senggang dan kegiatan hiburan yang membentuk kehidupan sehari-hari mayoritas masyarakat (Hall, ibid). 
Jurnal Ilmu Komunikasi UHO : Jurnal Penelitian Kajian Ilmu Komunikasi dan Informasi.

Volume 6, No. 2, April 2021, hlm 141-155

Budaya terus berubah, tetapi budaya merupakan wujud dan ekspresi dari sikap, makna, dan nilai bersama. Budaya merupakan sesuatu yang disukai dan dilakukan oleh banyak orang dalam suatu masyarakat, kelompok, dll. (Roßmeier, 2019: 2). Beberapa ahli berpendapat bahwa budaya merupakan cerminan dari pemimpin (Gruenert dan Whitaker, 2019: 1). Berdasarkan hasil penelitian Gruenert dan Whitaker, dibutuhkan waktu setidaknya lima tahun bagi sebuah budaya untuk berubah. Setelahnya baru akan terjadi stagnasi budaya.

Jika berbicara tentang budaya, maka akan selalu melibatkan unsur-unsur budaya itu sendiri. Unsur budaya dibedakan menjadi material dan non material (Barkan, 2019). Budaya material adalah semua benda fisik masyarakat, termasuk alat dan teknologinya, pakaian, alat makan, dan alat angkutnya. Sedangkan budaya non-material disebut juga sebagai budaya simbolik yang terdiri dari nilai-nilai, kepercayaan, simbol, dan bahasa yang mendefinisikan masyarakat.

Nishimura, Nevgi, dan Tella berpendapat bahwa orang-orang dari negara yang berbeda berkomunikasi secara berbeda karena latar belakang budaya dan referensi masing-masing yang seringkali menimbulkan kesalahpahaman (Seregina dan Schouten, 2016). Menurut teori konteks Hall, people from different cultures may respond differently to information (Hornikx dan Le Pair, 2017: 228). Artinya, orang-orang dari budaya yang berbeda mungkin menanggapi informasi secara berbeda. Hornikx dan Le Pair menjelaskan bahwa latar belakang budaya seseorang mempengaruhi seberapa baik mereka dapat memahami pesan yang kompleks, serta seberapa baik mereka menghargai pesan tersebut (Hornikx dan Le Pair, ibid).

Berdasarkan uraian di atas, budaya dapat diartikan sebagai kepercayaan, pakaian, alat makan, bahasa, simbol, teknologi, transportasi, dan nilai-nilai yang dimiliki bersama, disukai, dan dilakukan oleh banyak orang dalam suatu masyarakat atau kelompok. Seiring dengan perkembangan zaman, kebudayaan bergerak secara dinamis dan terus berubah. Latar belakang budaya dan referensi tidak hanya mempengaruhi bagaimana orang menginterpretasi informasi tetapi juga bagaimana informasi itu dikonstruksi.

Peirce menjelaskan bahwa semua cara berpikir bergantung pada penggunaan tanda, setiap pikiran adalah tanda, dan setiap tindakan penalaran terdiri dari interpretasi tanda (Balsin, Jumaidin, dan Masrul, 2018). Hall menjelaskan bahwa semiotik adalah studi atau "ilmu tentang tanda," dan peran utamanya ialah sebagai wahana pemaknaan dalam budaya (Hall, 2015: 6). Semiotics studies the production, transmission, and interpretation of meaning represented symbolically in signs and messages, primarily but not exclusively in the language 
Jurnal Ilmu Komunikasi UHO : Jurnal Penelitian Kajian Ilmu Komunikasi dan Informasi.

Volume 6, No. 2, April 2021, hlm 141-155

(Mingers dan Willcocks, 2017: 17). Dapat diartikan bahwa semiotika mempelajari produksi, transmisi, dan interpretasi makna yang direpresentasikan secara simbolis dalam tanda dan pesan, terutama tetapi tidak secara eksklusif dalam bahasa.

Menurut Sobur, tanda membantu manusia berkomunikasi satu sama lain, dan metode untuk mempelajari tanda disebut semiotik (Sobur, 2017: 15). Eco dalam Sobur membedakan semiotika menjadi dua jenis, semiotika komunikasi dan makna (Sobur, ibid). Peirce berpendapat bahwa doktrin tanda; menyusun bahasa, sistem komunikasi, dan hal-hal lain yang berkaitan dengan pikiran manusia (Sobur, 2017: 13). Hal tersebut disebabkan karena tanda verbal dan nonverbal membantu manusia untuk membangun pemahaman tentang realitas. Dengan demikian, bahasa merupakan sistem komunikasi fundamental yang terdiri dari tanda-tanda bermakna yang dikomunikasikan berdasarkan relasi.

Menurut Grabarczyk, teori de Saussure menunjukkan bahwa semiotika seharusnya hanya berpegang pada tanda dan konsep yang mereka ekspresikan. Saussure explains that the signifier is the sign itself, which often identifies with the sign's sound or an image. Meanwhile, the signified is the meaning of a word (Grabarczyk, 2019: 88). Artinya, Saussure menjelaskan bahwa penanda adalah tanda itu sendiri, yang seringkali diidentikkan dengan bunyi tanda atau gambar. Sedangkan pertanda adalah arti dari sebuah kata. Ini dipahami sebagai konsep atau ide dalam pikiran pengguna bahasa (Grabarczyk, ibid).

Kekhususan lain dari model Saussure adalah perbedaan antara language atau bahasa dan parole atau tuturan. Menurut Littlejohn, bahasa merupakan sistem komunikasi formal yang dapat dianalisis secara terpisah dari penggunaannya dalam kehidupan sehari-hari. Sedangkan tuturan adalah penggunaan bahasa untuk menyampaikan tujuan tertentu (Vera, 2015: 19). Vera menjelaskan bahwa model diadik Saussure, secara singkat, merupakan makna dari semua hubungan antara penanda dan pertanda (Vera, 2015: 20). Dengan demikian, karena hubungan antara penanda dan pertanda merupakan bagian dari konvensi sosial, maka tanda-tanda yang muncul mewakili budaya di mana mereka digunakan.

Oleh karena itu, apabila bahasa merupakan salah satu elemen budaya yang terdiri dari tanda-tanda bermakna yang digunakan untuk mewakili dunia, struktur kalimat dan kata-kata yang digunakan pada iklan layanan masyarakat KEMENKES merepresentasikan nilai-nilai budaya Indonesia. Dengan demikian, untuk mengkaji dan menggali nilai-nilai budaya tersebut, penulis melakukan analisis semiotik pada iklan layanan masyarakat KEMENKES. Metode yang digunakan pada penelitian ini adalah model analisis semiotik Ferdinand De 
Jurnal Ilmu Komunikasi UHO : Jurnal Penelitian Kajian Ilmu Komunikasi dan Informasi.

Volume 6, No. 2, April 2021, hlm 141-155

Saussure. Maka, rumusan masalah penelitian ini ialah bagaimana representasi elemen budaya kolektivis pada iklan Covid-19 Kementerian Kesehatan Republik Indonesia?

\section{METHODE PENELITIAN}

Nauta menekankan bahwa analisis semiotik menggambarkan makna dan penerapan suatu bahasa sasaran (Sobur, 2017: 19). Cultural analysts in sociology typically cite Ferdinand de Saussure's work to motivate a narrow theory of meaning (Stoltz, 2019: 1). Dapat diartikan bahwa analis budaya dalam sosiologi biasanya mengutip karya Ferdinand de Saussure untuk memotivasi teori makna yang sempit. Dengan kata lain, semiotik adalah pendekatan untuk mengeksplorasi bagaimana komunikator menggunakan tanda ketika mengatakan sesuatu yang berarti kepada orang lain. Sedangkan makna dari tanda-tanda tersebut merupakan resentasi dari nilai-nilai budaya komunikator.

Model semiotik Saussure mempelajari hubungan antara tanda (teks dan gambar) dan maknanya (Puspitasari, 2019). Model Saussure memecah tanda visual menjadi dua kategori, yaitu denotasi, dan konotasi. Keduanya menggambarkan hubungan antara penanda dan pertanda, namun masing-masing memiliki arti yang berbeda (Persada, 2020: 1). Secara singkat, denotasi adalah makna literal dari suatu tanda, sedangkan konotasi adalah gagasan atau perasaan yang dimunculkan oleh suatu tanda selain makna utamanya. Kemudian, masing-masing akan saling berhubungan dan menjelaskan makna kontekstual dari keseluruhan tanda.

Yin menjelaskan, unit analysis is a component that is essentially related to determining what is meant by a case in the research concerned (Aspers dan Corte, 2019: 142). Artinya, unit analisis merupakan suatu komponen yang pada dasarnya terkait dengan penentuan apa yang dimaksud dengan suatu kasus dalam penelitian yang bersangkutan. Chambliss dan Schutt berpendapat bahwa analisis unit adalah hal-hal dan perilaku yang ingin dipelajari dan dipahami oleh peneliti (Hanel dan Mehler, 2019). Penelitian ini menganalisis iklan layanan masyarakat KEMENKES dengan menggunakan model analisis semiotik Ferdinand De Saussure. Paradigma penelitian ini adalah konstruktivisme, dengan pendekatan kualitatif. Materi penelitiannya adalah iklan layanan masyarakat pertama yang dipublikasikan pada situs resmi KEMENKES. 
Jurnal Ilmu Komunikasi UHO : Jurnal Penelitian Kajian Ilmu Komunikasi dan Informasi. Volume 6, No. 2, April 2021, hlm 141-155

\section{HASIL DAN PEMBAHASAN}

People from a low-context culture are expected to have more challenges comprehending complex messages and, consequently, to appreciate them less than people from a high-context culture (Hornikx dan Le Pair, 2017: 228). Dapat diartikan, orang-orang dari budaya konteks rendah (individualis) diyakini memiliki lebih banyak tantangan dalam memahami pesan-pesan tersirat dan, akibatnya, mereka kurang mengapresiasi pesan konpleks daripada orang-orang dari budaya konteks tinggi (kolektivis). Teori konteks Hall menunjukkan bahwa setiap budaya memiliki preferensi berbeda dalam membentuk dan pesan, sebagian memilik pesan tersirat lainnya lebih menyukai pesan yang eksplisit (Hornikx dan Le Pair, 2017: 230). Dengan kata lain, sebagian besar informasi dalam budaya konteks tinggi (kolektivis) anatra ada dalam konteks fisik atau terinternalisasi dalam diri seseorang, dan sangat sedikit yang mengandung makna tersurat/eksplisit, dalam penyampaiannya. Sementara pada budaya konteks rendah (individualis) adalah kebalikannya, yaitu, informasi disimpan dengan menggunakan tanda-tanda yang eksplisit.

Prinsip dasar model analisis semiotik Saussure adalah bahasa merupakan sistem tanda yang terdiri dari dua bagian, penanda dan pertanda. Penanda adalah bentuk media yang diambil dari tanda, seperti bunyi, gambar, atau guratan yang membentuk kata-kata pada selembar kertas. Sedangkan pertanda adalah konsep dan makna (Vera, 2015: 70). Oleh karena itu, untuk mengidentifikasi unsur-unsur budaya kolektivis pada iklan layanan masyarakat pencegahan Covid-19 versi Kementerian Kesehatan (KEMKES) Republik Indonesia, penulis menggunakan model analisis semiotik Saussure.

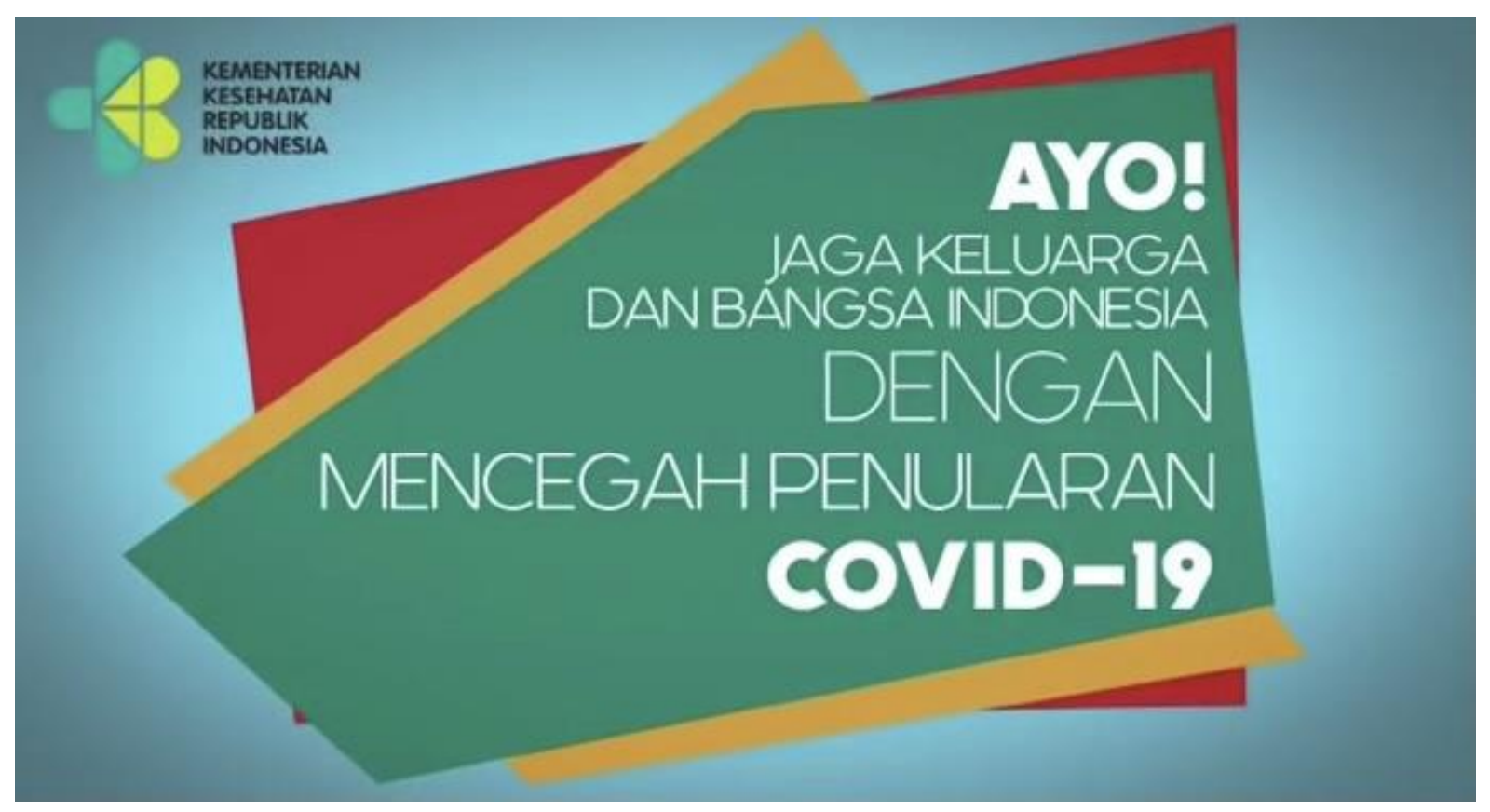

ISSN: 2527-9173. Website: http://ojs.uho.ac.id/index.php/KOMUNIKASI/index 
Jurnal Ilmu Komunikasi UHO : Jurnal Penelitian Kajian Ilmu Komunikasi dan Informasi.

Volume 6, No. 2, April 2021, hlm 141-155

Sumber: KEMKESRI, 2020

Gambar 1 Iklan Layanan Masyarakat: Pencegahan Covid-19 KEMENKESRI

Sebagaimana yang tampak di atas, visual terdiri dari kumpulan tulisan, warna, logo dan bangun datar asimetris. Jika dipersempit visual dapat dibagi menjadi sembilan bagian yaitu: simbol berwarna hijau dan kuning diikuti dengan tulisan KEMENTERIAN KESEHATAN REPUBLIK INDONESIA (logo), AYO! (tulisan 1), JAGA KELUARGA DAN BANGSA INDONESIA (tulisan 2), DENGAN MENCEGAH PENULARAN (tulisan 3), COVID-19 (tulisan 4), latar belakang tulisan berwarna hijau (bangun asimetris 1), latar belakang tulisan berwarna kuning (bangun asimetris 2), latar belakang tulisan berwarna merah (bangun asimetris 3), latar belakang utama berwarna biru terang agak kehitaman (latar belakang visual). Untuk lebih mudah dalam memahaminya, penulis membuat tabel analisis sebagai berikut:

Table 1 Model Analisis Semiotik Saussure

\begin{tabular}{|c|c|c|}
\hline No & Penanda & Pertanda \\
\hline 1 & $\begin{array}{l}\text { Simbol berwarna hijau dan } \\
\text { kuning diikuti dengan tulisan } \\
\text { KEMENTERIAN } \\
\text { KESEHATAN REPUBLIK } \\
\text { INDONESIA. }\end{array}$ & $\begin{array}{l}\text { Simbol dan tulisan merupakan logo KEMENKES } \\
\text { RI. }\end{array}$ \\
\hline 2 & Tulisan AYO! & $\begin{array}{l}\text { Kata yang dicetak tebal tersebut mengartikan } \\
\text { ajakan. }\end{array}$ \\
\hline 3 & $\begin{array}{lr}\text { Tulisan JAGA } & \text { KELUARGA } \\
\text { DAN } & \text { BANGSA } \\
\text { INDONESIA. } & \end{array}$ & $\begin{array}{l}\text { Kata yang ditulis dengan huruf kapital tersebut } \\
\text { merupakan instruksi. }\end{array}$ \\
\hline 4 & $\begin{array}{l}\text { Tulisan } \\
\text { MENCEGAH } \\
\text { PENULARAN. }\end{array}$ & $\begin{array}{l}\text { Kata yang ditulis dengan huruf kapital yang } \\
\text { ukurannya lebih besar tersebut merupakan } \\
\text { keterangan yang melengkapi tulisan pada bagian } \\
\text { sebelumnya. }\end{array}$ \\
\hline 5 & Tulisan COVID-19. & $\begin{array}{l}\text { Kata yang dicetak tebal tersebut merupakan } \\
\text { objek yang yang mendapatkan perlakuan, atau } \\
\text { hal yang perlu dicegah. }\end{array}$ \\
\hline 6 & $\begin{array}{l}\text { Bangun asimetris berwarna } \\
\text { hijau. }\end{array}$ & $\begin{array}{l}\text { Merupakan latar belakang tulisan. Warna hijau } \\
\text { diasosiasikan dengan rasa nyaman dan netralitas } \\
\text { (Levy, 1984). }\end{array}$ \\
\hline 7 & $\begin{array}{l}\text { Bangun asimetris berwarna } \\
\text { kuning. } \\
\text { Bangun asimetris berwarna } \\
\text { merah. }\end{array}$ & $\begin{array}{l}\text { Merupakan latar belakang tulisan. Warna merah, } \\
\text { oranye dan kuning termasuk kategori warna- } \\
\text { warna hangat yang diasosiasikan dengan } \\
\text { memancing perasaan aktif; membangkitkan } \\
\text { emosi dan gairah (Levy, ibid). }\end{array}$ \\
\hline
\end{tabular}

ISSN: 2527-9173. Website: http://ojs.uho.ac.id/index.php/KOMUNIKASI/index 
Jurnal Ilmu Komunikasi UHO : Jurnal Penelitian Kajian Ilmu Komunikasi dan Informasi.

Volume 6, No. 2, April 2021, hlm 141-155

\begin{tabular}{|l|l|l|} 
& &
\end{tabular}

Sumber: Hasil Analisis, 2021.

Berdasarkan gambar 1 dan tabel 1 diketahui bahwa iklan Covid-19 versi Kementerian Kesehatan (KEMKES) Republik Indonesia merupakan iklan layanan masyarakat yang berisi ajakan untuk mencegah penularan Covid-19 demi melindungi keluarga dan bangsa Indonesia. Berdasarkan hasil identifikasi tanda-tanda yang ditemukan, diketahui bahwa pesan dapat dikategorikan kompleks karena tidak dapat langsung dipahami. Walaupun secara Bahasa kalimat disusun dengan pola komunikasi langsung, masih ada sejumlah diksi yang membutuhkan penjelasan dan interpretasi lebih lanjut, seperti: siapa saja yang termasuk keluarga dan bangsa Indonesia, serta bagaimana cara mencegah penularan Covid-19.

Sebagaimana yang telah penulis uraikan pada bagian sebelumnya, tanda-tanda pada iklan merupakan representasi dari budaya komunikator. Iklan layanan masyarakat yang dianalisis pada penelitian ini diproduksi dan dipublikasikan oleh Kementerian Kesehatan (KEMKES) Republik Indonesia. Karena KEMKES merupakan lembaga negara, maka dapat diasumsikan bahwa nilai-nilai budaya pada iklan layanan masyarakat tersebut mencerminkan budaya dominan di Indonesia. Karena budaya memiliki sejumlah unsur, dalam penelitian ini penulis membatasi elemen yang diamati berdasarkan teori budaya konteks Hall.

\section{Representasi Budaya Konteks Tinggi (Kolektivis)}

Konsep linguistik dan budaya (Novikova, dkk., 2018: 241), serta tanda-tanda yang muncul dalam proses komunikasi Balsin, Jumaidin dan Masrul (2018), merupakan reresentasi norma-norma perilaku dan nilai-nilai esensi dan substansi budaya dalam masyarakat pada tahap perkembangan budaya tersebut. Maka, tanda-tanda yang ditemukan pada iklan layanan masyarakat Covid-19 Kementerian Kesehatan Republik Indonesia merupakan representasi dari budaya mayoritas di Indonesia pada era kenormalan baru.

Teori Hall membagi budaya kedalam dua kategori, yaitu konteks rendah dan konteks tinggi. Karakteristik utama komunikasi pada negara dengan budaya konteks rendah ialah informasi tersedia secara eksplisit, komunikasi langsung, semua informasi penting diintegrasikan ke dalam percakapan, percakapan tidak berbelit-belit, serta pesan lebih lugas ISSN: 2527-9173. Website: http://ojs.uho.ac.id/index.php/KOMUNIKASI/index 
Jurnal Ilmu Komunikasi UHO : Jurnal Penelitian Kajian Ilmu Komunikasi dan Informasi.

Volume 6, No. 2, April 2021, hlm 141-155

dan lebih mudah dipahami. Sedangkan pola komunikasi di negara dengan budaya konteks tinggi adalah sebaliknya, yaitu: informasi umumnya tersirat; status, pangkat, dan hierarki sangat penting; pesan membutuhkan interpretasi; emosi ditransmisikan; akibatnya, makna pesan menjadi lebih sulit untuk dipahami. Beberapa peneliti berpendapat bahwa men generally tend to be more direct in communicating, while women's communication is more covert and emotional (Frank, Enkawa, dan Schvaneveldt, 2015: 268). Artinya, pria umumnya cenderung lebih langsung dalam berkomunikasi, sedangkan komunikasi perempuan lebih terselubung dan emosional.

Menurut laporan tahunan Prof Geert Hofstede, pada tahun 2019, Indonesia memperoleh nilai 14 dari 120 poin pada indeks individualisme (Hofstede, 2019). Hasilnya menjadikan Indonesia berada di peringkat tertinggi keenam pada daftar negara dengan tingkat budaya kolektivis, dari total 66 negara yang diteliti. Pada penelitian ini, penulis juga berupaya untuk mengkaji hasil identifikasi tanda-tanda pada iklan layanan masyarakat KEMENKES dengan merujuk pada karakteristik budaya berdasarkan teori konteks Hall.

Berdasarkan hasil observasi, diketahui bahwa informasi disampaikan dalam kalimat dan frase sederhana. Namun, sejumlah tanda yang digunakan kurang eksplisit serta membutuhkan intepretasi dan penjelasan lebih rinci. Alhasil, pesan yang disampaikan lebih sulit untuk dipahami, dan cenderung berpotensi menimbulkan kebingungan bagi sejumlah kalangan masyarakat. Sebagai pembanding, penulis melampirkan salah satu iklan layanan masyarakat yang pertama dipublikasi oleh Departemen Pusat Pengendalian Penyakit (CDC) yang merupakan institusi di bawah naungan Kementerian Kesehatan Amerika Serikat.

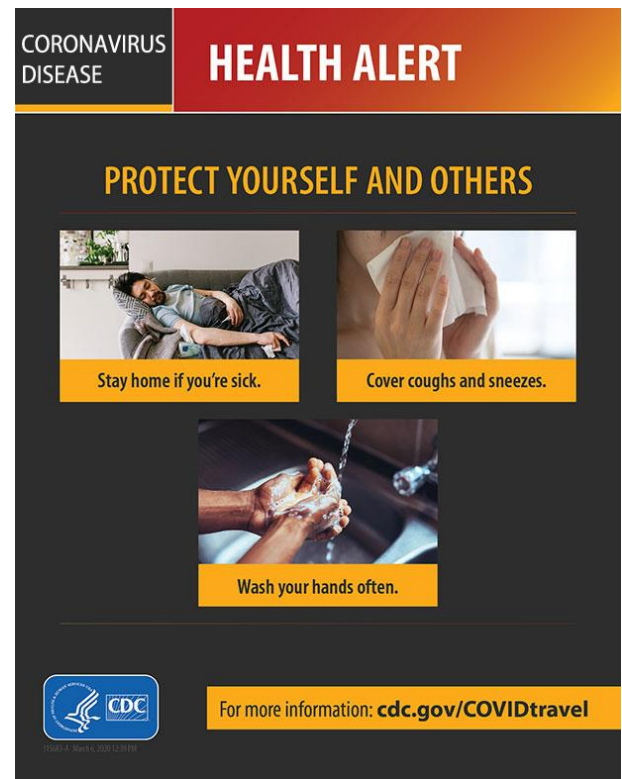

Sumber: CDC, 2020

\section{Gambar 2 Iklan Peringatan Perjalanan CDC}

ISSN: 2527-9173. Website: http://ojs.uho.ac.id/index.php/KOMUNIKASI/index 
Jurnal Ilmu Komunikasi UHO : Jurnal Penelitian Kajian Ilmu Komunikasi dan Informasi.

Volume 6, No. 2, April 2021, hlm 141-155

Sebagaimana yang tampak pada gambar, diketahui bahwa tanda-tanda pada iklan peringatan perjalanan CDC sangat sederhana dan eksplisit. Dua figur laki-laki berbanding dengan satu figur perempuan merepresentasikan karakteristik maskulinitas yang dominan. CDC menggunakan sejumlah tanda universal yang dapat diartikan oleh masyarakat luas, termasuk penggunaan latar belakang gelap sebagai representasi dari kondisi yang kelam; latar belakang putih dan polos pada gambar menunjukkan kebersihan; sofa, bantal, dan wastafel mewakili interior rumah; huruf besar tebal untuk menekankan informasi tertentu; serta logo CDC serta alamat situs web menunjukkan formalitas poster (resmi), sekaligus rujukan untuk mendapat informasi yang lebih lengkap.

Sejumlah ahli komunikasi termasuk Hall berpendapat bahwa budaya konteks rendah cenderung identik dengan budaya maskulin. Sebaliknya, budaya konteks tinggi cenderung diidentikkan dengan budaya feminim. Jika demikian, secara teoritis, negara berbudaya kolektivis seperti Indonesia harusnya berada di peringkat bawah pada indeks budaya maskulin. Namun, laporan Prof. Geert Hofstede tahun 2019, menunjukkan bahwa Indonesia memperoleh nilai 46 dari 120 poin pada indeks maskulinitas, menjadikan Indonesia berada di peringkat 22 dari 66 negara yang diteliti (Hofstede, 2019). Maka, tingkat kolektivitas sebuah budaya tidak selalu berbanding terbalik dengan tingkat maskulinitas.

Singkatnya, karakteristik budaya konteks tinggi yang ditemukan pada iklan layanan masyarakat KEMKES ialah sebagai berikut:

Table 2 Karakteristik Budaya Konteks Tinggi pada Iklan Covid-19 KEMKES

\begin{tabular}{|c|c|c|}
\hline No & Indikator & Penanda \\
\hline 1 & Informasi & $\begin{array}{l}\text { Informasi yang disampaikan jelas, namun kurang } \\
\text { lengkap sehingga berpotensi menimbulkan } \\
\text { kebinoungan }\end{array}$ \\
\hline 2 & Komunikasi langsung & $\begin{array}{l}\text { Kalimat yang digunakan sederhana, namun } \\
\text { sejumlah kata membutuhkan interpretasi dan/ } \\
\text { penjelasan lebih lanjut. }\end{array}$ \\
\hline 3 & Informasi penting & $\begin{array}{l}\text { Informasi penting hanya menjaga keluarga dan } \\
\text { bangsa Indonesia dan mencegah penularan Covid- } \\
19 \text {. }\end{array}$ \\
\hline 4 & Pertukaran langsung & $\begin{array}{l}\text { Tidak ada pertukaran langsung, dalam hal ini, tidak } \\
\text { tersedia rujukan ke alamat situs resmi KEMKES. }\end{array}$ \\
\hline 5 & Keterbacaan & $\begin{array}{l}\text { Pilihan frase cukup sederhana, aksen-aksen warna } \\
\text { yang digunakan juga cukup membangun suasana } \\
\text { sesuai dengan situasi saat iklan pertama } \\
\text { diluncurkan. }\end{array}$ \\
\hline
\end{tabular}

Sumber: Hasil Analisis Unsur-Unsur Budaya Konteks Tinggi, 2021.

ISSN: 2527-9173. Website: http://ojs.uho.ac.id/index.php/KOMUNIKASI/index 
Jurnal Ilmu Komunikasi UHO : Jurnal Penelitian Kajian Ilmu Komunikasi dan Informasi. Volume 6, No. 2, April 2021, hlm 141-155

\section{KESIMPULAN}

Berdasarkan hasil penelitian diketahui bahwa tanda-tanda yang terdapat pada iklan layanan masyarakat pencegahan penularan Covid-19 versi Kementerian Kesehatan Republik Indonesia disusun secara sederhana, menggunakan struktur kalimat langsung. Namun, sejumlah diksi yang digunakan masih membutuhkan interpretasi dan/ penjelasan lanjutan untuk dapat menghasilkan dampak berupa tindakan pencegahan sebagaimana yang diinginkan. Hasil penelitian menunjukkan tanda-tanda pola komunikasi yang ditemukan merepresentasi budaya dominan di Indonesia, yaitu budaya konteks tinggi dengan tingkat nilai kolektivisme yang tinggi sebagaimana indeks budaya tahunan Prof. Hofstede.

Singkatnya, tanda-tanda yang dipilih dan ditampilkan pada iklan layanan masyarakat tentang Covid-19 yang penulis diteliti dipengaruhi oleh latar belakang dan referensi budaya komunikator, yaitu Kementerian Kesehatan Republik Indonesia, yang sebagai instirusi pemerintah dapat diasumsikan mewakili budaya mayoritas di Indonesia. Maka, apabila pesan pada iklan diterjemahkan kedalam bahasa asing, besar kemungkinan kompleksitas pesan tidak dapat menjangkau warga negara asing dari negara-negara konteks rendah yang ada di Indonesia.

Penulis berharap hasil penelitian ini dapat memotivasi lebih banyak akademisi untuk melakukan penelitian serupa yang mengkaji tanda-tanda yang merepresentasi nilai-nilai budaya pada iklan, di mana tanda tersebut dipublikasikan. Iklan tentang Covid-19 bisa menjadi objek yang tepat untuk mengeksplorasi representasi dari unsur-unsur budaya berdasarkan teori konteks Hall, mengingat pemerintah dari negara-negara terdampak telah mengeluarkan sejumlah materi publikasi serupa. Berdasarkan penelitian ini, diketahui bahwa riset multidisiplin terkait model penyampaian pesan yang lebih universal dibutuhkan untuk membantu meningkatkan efektivitas dan jangkauan dari informasi yang disampaikan. Sehingga pesan-pesan, khususnya pesan kemasyarakatan dapat menembus batas-batas budaya. 
Jurnal Ilmu Komunikasi UHO : Jurnal Penelitian Kajian Ilmu Komunikasi dan Informasi.

Volume 6, No. 2, April 2021, hlm 141-155

\section{DAFTAR PUSTAKA}

Aspers, P., dan Corte, U. (2019). What is Qualitative in Qualitative Research. Qual Sociol, 42, 139-160, DOI: 10.1007/s11133-019-9413-7.

Balsin, B.A., Jumaidin, L.O., dan Masrul. (2018). Analisis Semiotik Ritual Tradisi "Haroa" Potong Rambut (Aqiqah) pada Masyarakat Suku Buton di Kecamatan Kendari Barat Kota Kendari. Jurnal Ilmu Komunikasi UHO: Jurnal Penelitian Kajian Ilmu Komunikasi dan Informasi, 3(2), 17-28, ISSN: 2527-9173.

Barkan, S.E. (2019). Sociology: Understanding and Changing the Social World. North Carolina, USA: University of North Carolina Press.

Frank, B., Enkawa, T., dan Schvaneveldt, S.J. (2015). The role of individualism vs. collectivism in the formation of repurchase intent: A cross-industry comparison of the effects of cultural and personal values. Journal of Economic Psychology, 51, 261-278, DOI: 10.1016/j.joep.2015.08.008.

Google News. (2021, 7 Maret). Coronavirus (COVID-19) Indonesia. Google News. news.google.com/covid19/map?hl=en-INA.

Grabarczyk, P. (2019). Directival Theory of Meaning: From Syntax and Pragmatics to Narrow Linguistic Content. New York, USA: Springer International Publishing.

Gruenert, S., dan Whitaker, T. (2019). Committing to the Culture: How Leaders Can Create and Sustain Positive Schools. Virginia, USA: ASCD.

Hall, S. (2015). REPRESENTATION: Cultural Representations and Signifying Practices. London, UK: SAGE Publications Ltd.

Hanel, P.H.P., dan Mehler, D.M.A. (2019). Beyond reporting statistical significance: Identifying informative effect sizes to improve scientific communication. Public Understanding of Science, 28(4), 468-485, DOI: 10.1177/0963662519834193.

Hofstede, G. (2019, Desember). Individuality Index. Clearly Cultural. https://clearlycultural.com/geert-hofstede-cultural-dimensions/individualism/.

....... (2019, Desember). Masculinity Index. Clearly Cultural. https://clearlycultural.com/geert-hofstede-cultural-dimensions/masculinity/.

Hornikx, J., dan Le Pair, R. (2017). The Influence of High-/Low-Context Culture on Perceived Ad Complexity and Liking. Journal of Global Marketing, 30(4), 228-237, DOI: 10.1080/08911762.2017.1296985.

Kementerian Kesehatan Republik Indonesia. (2020, 15 Maret). Kesiapsiagaan Menghadapi Infeksi COVID-19. kemkes.go.id/web/assets/images/covid-19.png.

Levy, B.I. (1984). Research into the psychological meaning of color. American Journal of Art Therapy, 23(2), 58-62.

Mingers, J., dan Willcocks, L. (2017). An integrative semiotic methodology for IS research. Information and Organization, 27(1), 17-36, DOI: 10.1016/j.infoandorg.2016.12.001.

Novikova, I., et al. (2018). Lexical and semantic representation of the linguistic and cultural concept "Rest" in the English, German, and Russian languages. Opción: Revista de Ciencias Humanas y Sociales, 85, 237-256, ISSN 1012-1587. 
Jurnal Ilmu Komunikasi UHO : Jurnal Penelitian Kajian Ilmu Komunikasi dan Informasi.

Volume 6, No. 2, April 2021, hlm 141-155

Persada, S.I.P. (2020). Semiotic Analysis of Gundala Movie Poster. Advances in Social Science, Education and Humanities Research, 391, 133-135, DOI: 10.2991/assehr.k.200108.029.

Puspitasari, F. (2019). The user understanding of Instagram's GIF in social media based on Saussure's semiotics. Diploma thesis. Bandung, Indonesia: UIN Sunan Gunung Djati Bandung.

Roßmeier, C. (2019). The Origins of Popular Culture and "Beatlemania" in Britain. München, Germany: GRIN Verlag.

Seregina, A., dan Schouten, J.W. (2017). Resolving identity ambiguity through transcending fandom. Consumption Markets \& Culture, 20(2), 107-130, DOI: 10.1080/10253866.2016.1189417.

Sobur, A. (2017). Semiotika Komunikasi. Bandung, Indonesia: PT Remaja Rosdakarya Offset.

Stewart, P.J., dan Strathern, A.J. (2017). Language and Culture. Breaking the Frames: Anthropological Conundrums, 69-78, DOI: 10.1007/978-3-319-47127-3_8.

Stoltz, D.S. (2019). Becoming a dominant misinterpreted source: The case of Ferdinand de Saussure in cultural sociology. Journal of Classical Sociology, 19, 1-22, DOI: $10.1177 / 1468795 \times 19896056$.

The Centers for Disease Control and Prevention. (2020, 6 Maret). Health Alert: For All Travelers. cdc.gov/coronavirus/2019-ncov/images/health-alert.

Vera, N. (2015). Semiotika dalam Riset Komunikasi. Ciawi, Bogor: Ghalia Indonesia.

Wexner, L. B. (1954). The degree to which colors (hues) are associated with mood-tones. Journal of Applied Psychology, 38(6), 432-435. 